\title{
HEMANGIOENDOTELIOMA EPITELIOIDE DE PENE
}

\author{
R. GUTIÉRREZ GARCÍA, J.M. CAPDEVILA HERNÁNDEZ, J. PINTO BLÁZQUEZ*, \\ F.J. PÉREZ GARCÍA, J.M. LANZAS PRIETO, C.L. MENÉNDEZ FERNÁNDEZ*
}

Servicio de Urología. *Anatomía Patológica. Hospital San Agustín. Avilés (Asturias).

Actas Urol Esp. 28 (10): 771-773, 2004

\section{RESUMEN}

HEMANGIOENDOTELIOMA EPITELIOIDE DE PENE

Describimos un HE de pene en un varón de 64 años. Se trata de un tumor vascular de potencial maligno intermedio entre un hemangioma y un angiosarcoma de muy escasa aparición en esta localización. Su tratamiento comprende la extirpación amplia y la vigilancia una vez descartada la presencia de metástasis o multifocalidad. La histopatología es esencial en el diagnóstico.

PALABRAS CLAVE: Hemangioendotelioma epitelioide. Tumor genital.

\section{ABSTRACT}

\section{EPITHELIOID HEMANGIOENDOTHELIOMA OF PENIS}

A case of $\mathrm{EH}$ of the penis in a sixtyfour-year-old patient is described. This is a rare -in this location- vascular tumor of borderline malignant potential between hemangioma and angiosarcoma. Local excision of the tumor with a cut-off of normal tissue and careful follow-up of the patient is the accepted procedure. Immunohistochemistry is essential for the diagnosis.

KEY WORDS: Epithelioid hemangioendothelioma. Genital tumor.

$\mathrm{E}_{\mathrm{fit}}^{1}$ término hemangioendotelioma epitelioide fue acuñado por Weiss y Enzinger en 1982 para denominar un tipo de tumores vasculares de morfología y comportamiento intermedio entre el hemangioma y el angiosarcoma ${ }^{1}$. Descrita inicialmente en partes blandas, también aparece en la piel, hígado, pulmón, hueso, cerebro, cavidad oral, estómago, mediastino, bazo, corazón, peritoneo y prácticamente cualquier localización anatómica, pudiendo ser únicos o multifocales ${ }^{2}$. Sin embargo, la localización en pene es rara. Hemos encontrado nueve casos comunicados desde $1982^{1,3-6}$, si bien ya se ha comunicado la localización en testículo ${ }^{7,8}$.

Presentamos un caso de hemangioendotelioma epitelioide en albugínea peneana.

\section{CASO CLÍNICO}

Paciente varón de 64 años con antecedentes de síndrome prostático, que consulta por dolor durante la erección y a la palpación en tercio proximal del pene en su cara dorsal. A la exploración se aprecia un nódulo móvil de consistencia fibroelástica que ya presentaba al menos seis meses antes.

La analítica sanguínea era normal y el estudio con ultrasonidos lo definió como nódulo hipoecogénico de más de $5 \mathrm{~mm}$.

Se procedió a extirpación-biopsia de un nódulo, de superficie lisa de $1,3 \times 0,7 \times 0,5 \mathrm{cms}$. de coloración roja-vinosa con áreas amarillentas y que se encontraba adherido a la albuginea del cuerpo cavernoso. Histológicamente la tumoración 
estaba bien delimitada, no encapsulada, con cierto aspecto lobular, patrón sólido y alta celularidad (Fig. 1). El tumor está formado por células fusiformes y epitelioides que se disponen en torno a espacios vasculares. Las células son de medianogran tamaño, de límites celulares bien definidos y muestran amplios citoplasmas eosinófilos, en alguno de los cuales se observan luces con hematíes en su interior que constituyen vasos neoformados (Fig. 2). Los núcleos son redondeados $u$ ovalados, con moderado pleomorfismo y con nucleolos visibles. Entre las células tumorales se observa escasa celularidad inflamatoria y pigmento hemosiderínico. No se observan áreas de necrosis y existe escaso número de mitosis (una o dos por 10 campos de gran aumento).

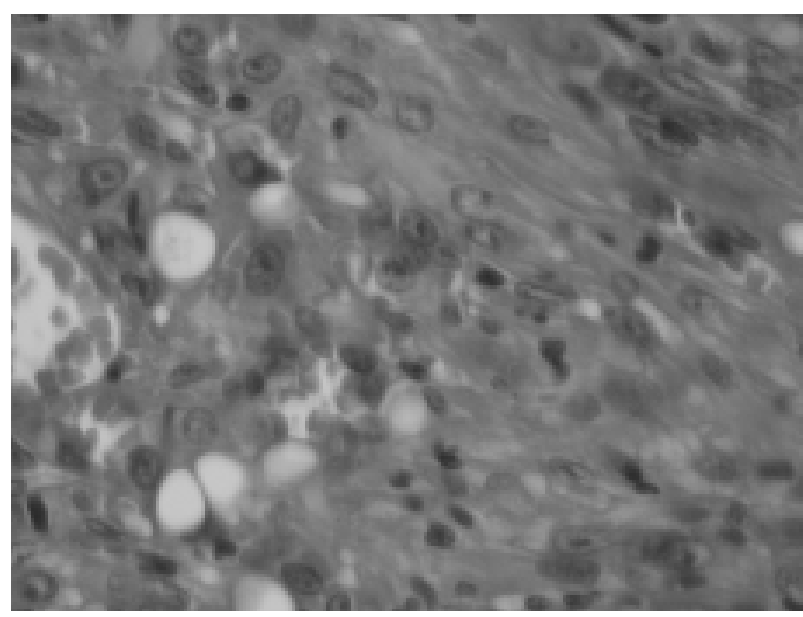

FIGURA 1. Tumor de patrón sólido, densamente celular con células fusiformes y epitelioides (He x 100).

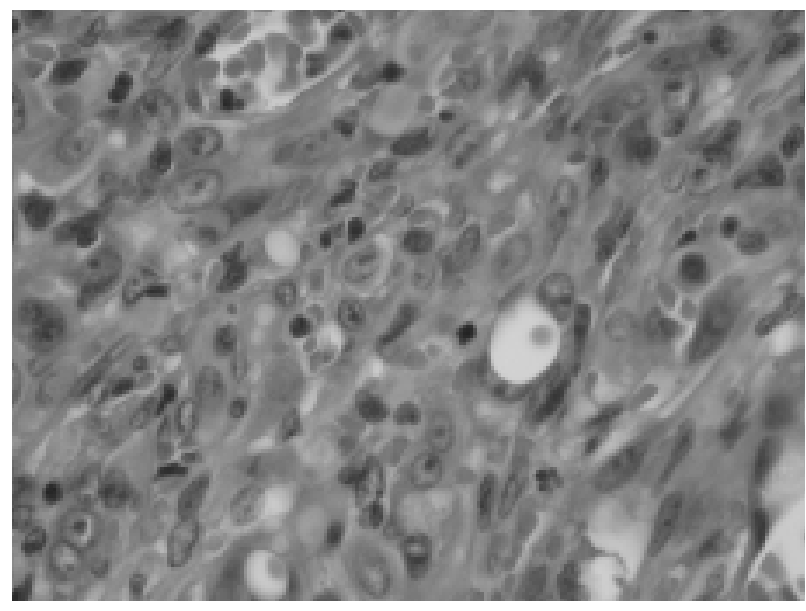

FIGURA 2. En alguna de las células tumorales se ven luces intracitoplasmáticas con hematies en su interior (He x 100).
La inmunohistoquímica confirma la existencia de positividad para factor VIII, CD31, CD34 y vimentina, siendo negativa la tinción para actina, HMB 45, pancitoqueratina y CAM 5.2. Presentaba un bajo índice proliferativo en la tinción con Ki-67.

En el momento actual, tras doce meses de seguimiento, sigue libre de tumor.

\section{DISCUSIÓN}

El diagnóstico del hemangioendotelioma epitelioide se basa en el estudio histopatológico, objetivando las características epitelioides de las células y evidenciando mediante inmunohistoquímica la positividad para marcadores vasculares.

Se trata de un tumor con varios centenares de casos comunicados en localización cutánea, de partes blandas y vísceras, presentando una evolución muy variable (desde libre de enfermedad hasta muerte por el tumor), pero con escaso índice de remisiones cuando aparecen metástasis, independientemente del tratamiento realizado. Recientemente se ha publicado la respuesta de un tumor hepático con afectación esplénica y peritoneal a la infusión de adriamicina ${ }^{9}$.

Teniendo en cuenta que Weiss y Enzinger comunican en su serie un $13 \%$ de recidivas locales y un $31 \%$ de metástasis, y que no se han podido encontrar factores pronósticos clínicos ni histopatológicos que permitan discriminar la diferente evolución de estos tumores, parece sensato mantener una vigilancia del paciente una vez extirpada la lesión. Mentzel y cols. abogan por considerar este tipo de neoplasias no como de grado intermedio o "borderline", sino como tumores totalmente malignos, aunque acepta un mejor pronóstico que los angiosarcomas.

En los nueve casos localizados en pene, algunos con un seguimiento de tres años, no se apreciaron recidivas ni metástasis, incluso en un caso que presentaba otras localizaciones cutáneas simultáneamente.

En conclusión, existe un acuerdo en la literatura en realizar un seguimiento cuidadoso de estos pacientes para detectar recidivas locales y/o metástasis, si bien no se han descrito en esta localización. Consideramos razonable descartar 
la presencia de otros tumores simultáneos y/o metástasis en hígado, pulmón y hueso tras el diagnóstico patológico, seguido de un seguimiento estrecho los primeros años, al menos hasta que dispongamos de factores pronósticos que nos permitan ajustar el tratamiento y el seguimiento al pronóstico de cada caso.

\section{REFERENCIAS}

1. Weiss SW, Enzinger FM. Epithelioid hemangioendothelioma. A vascular tumor often mistaken for a carcinoma. Cancer 1982;50:970-981.

2. Bollinger BK, Laskin WB, Knight CB. Epithelioid hemangioendothelioma with multiple site involvement. Literature review and observations. Cancer 1994;73:610-615.

3. Mentzel T, Beham A, Calonje E, Katemkamp D, Fletcher CDM. Epithelioid hemangioendothelioma of skin and soft tissues: Clinocopathologic and immunohistochemical study of 30 cases. Am J Surg Pathol 1997; 21(4): 363-374.

4. Guante M, Patel NK, Hill S, et al. Epithelioid hemangioendothelioma presenting in the skin. A clinicopathologic study of eight cases. Am J Dermatopathol. 1998,20:541-546.
5. Elhosseiny AA, Ramaswamy G, Healy RO. Epithelioid hemangioendothelioma of penis. Urology 1986;28:243-245.

6. Haidar A, Batman P. Epithelioid haemangioendothelioma of the penile shaft. Br J Urol 1995,75:796-797.

7. López Cubillana P, Asensio Egea LJ, Rigabert Montiel M, Server Pastor G, García Hernández JA, Giménez Bascuñana A. Hemangioendotelioma epitelioide paratesticular: un tumor vascular poco frecuente. Actas Urol Esp 1996;20(6): 591-592.

8. Tsolos C, Polychronidis A, Sivridis E, Kelidis G, Simopoulos C. Epithelioid hemangioendothelioma of the testis. J Urol 2001166: 1834.

9. Idilman R, Dokmeci A, Beyler AR, et al. Successful medical treatment of an epithelioid hemangioendothelioma of liver. Oncology 1997;54:171-175.

Dr. R. Gutiérrez García

Hospital San Agustín. Servicio de Urología.

Camino de Heros 4, 33400, Avilés.

(Trabajo recibido el 16 diciembre de 2003) 